\title{
An Observational Study for Causes of Surgical Jaundice at Tertiary Care Hospital
}

\author{
Priyanka yadav $^{*}$, Naveen Kumar Singh ${ }^{2}$
}

1Junior Resident, Department of General Surgery, Teerthanker Mahaveer Medical College \& Research Centre, Moradabad, Uttar Pradesh, India. Email: priyankayadav00790@gmail.com, Orcid ID: 0000-0002-7453-9266

2Professor \& Head, Department of General Surgery, Teerthanker Mahaveer Medical College \& Research Centre, Moradabad, Uttar Pradesh, India.

Email: dr.naveen.s@gmail.com,

Orcid ID: 0000-0001-7156-9817

${ }^{*}$ Corresponding author

Received: 30 November 2021

Revised: 11 January 2022

Accepted: 24 January 2022

Published: 18 February 2022

\begin{abstract}
Background: The etiological pattern of obstructive jaundice varies from one region to another due to higher incidence being noticed in the Northern region of India. Very limited studies have been carried out in the western regions of Uttar Pradesh. The various etiological parameters ranges from malignant biliary stricture, stone in the $\mathrm{CBD}$ and even secondaries lymph node compression at porta hepatis. Due to the transition from open surgery to the minimum invasive laproscopic surgery. The etiology related to surgical jaundice also become more common in relation to procedure related complications like CBD injury that leads to surgical jaundice. Material \& Methods: This present study has been conducted in the department of general surgery in TMMC and RC of a Tertiary Care hospital. In this observatory study the patients having clinical records of surgical jaundice who had attended the surgical Out Patient Department are going to be included. The time period of the study was from 1 jan 2020 to 30 sept 2021 . Overall, 44 patients were being considered. The selection of subject was done randomly and any type of special consideration regarding the gender of the patients was not being considered while selecting for the study. Results: In our study from 44 patients according to frequency distribution of etiology maximum of the subjects were having choledocholitheasis along with cholelitheasis that are $34.5 \%$ and choledocholitheasis with obstructive jaundice was the $2^{\text {nd }}$ most common cause with $31.78 \%$. The $3^{\text {rd }}$ most common etiology was found carcinoma of gall bladder with $11.35 \%$. Conclusions: It can be concluded that for the cases of malignant surgical jaundice good survival benefit usually depends upon the detection of the disease early during the course period. It has also been found that in malignant cases the stage of disease with jaundice were advanced. As per our study results it has been observed that there are various etiological factors contributing to development of surgical jaundice which needs multiple modes of precise investigations and further evaluations further studies and research needed to cover various factor responsible for surgical jaundice.
\end{abstract}

Keywords:- Surgical Jaundice.

\section{INTRODUCTION}

Jaundice is a generic term which is used for the cases in which patient have yellow pigmentation of the skin, sclera or mucous membranes which is caused due to the heterogeneous group of disorders. Basically due to the presence of elastin in abundance results in the predilection of sclera, which in turn tends to have a high affinity towards bilirubin. Obstructive jaundice has been commonly defined as a type of disease that is 
Annals of International Medical and Dental Research E-ISSN: 2395-2822 | P-ISSN: 2395-2814

Vol-8, Issue-2 | March-April 2022

DOI: 10.53339/aimdr.2022.8.2.12

Page no- 79-90 | Section- Research Article (General Surgery)

taking place because of the block in the pathway around the site of conjugation of the bile among the liver cells besides the entry of bile inside the duodenum with the help of ampulla.The block might also be either type of intrahepatic or extra hepatic across the bile duct. [1] There is a need of comprehensive study based on the gender and age distribution of the patients along with their clinical presentation and the etiology of the obstructive jaundice is indeed of some paramount importance while carrying out the appropriate management of the patients having surgical jaundice.[2] Both invasive and non-invasive diagnostic investigation are available in order to diagnose and carry out the proper diagnosis of the surgical jaundice.But several invasive investigations might be leading to cholangitis. Also the etiology of the cases of obstructive jaundice usually varies which depends on the age of the patient as well as the geographical region. Causes of surgical jaundice are:

- Choledochlitheasis

- Biliary atresia

- Choledochal cyst

- External compression over the bile duct

- Primary sclerosing cholangitis

- Biliary stricture. $[3,4]$

As the advance stages approaches the likelihood of the malignant diseases increases which are carcinoma around the head of pancreas,cholangiocarcinoma,klatskin tumour and some other types of malignant growth which compresses the bile duct. The diagnosis needs to be usually carried out through standard diagnostic processes like according to the history, biochemical test, physical examination and investigations. [5]
Several diagnostic and therapeutic challenges have been faced by the general surgeon while managing the surgical jaundice and these challenges have been mostly sound while practicing in the countries with limited resources. $[6,7]$

\section{MATERIAL AND METHODS}

This present study has been conducted in the department of general surgery in TMMC and RC of a Tertiary Care hospital. In this observatory study the patients having clinical records of surgical jaundice who had attended the surgical Out Patient Department are going to be included. The time period of the study was from 1 jan 2020 to 30 sept 2021 . Overall, 44 patients were being considered. The selection of subject was done randomly and any type of special consideration regarding the gender of the patients was not being considered while selecting for the study. With the help of the facilities available during the study period,all the necessary investigations have been carried out.

\section{Inclusion criteria}

1. The patient of Age above 18 years.

2. Patient having clinical evidence of surgical jaundice.

3. Patient having Any history of surgery for last 6 months.

4. Those patient who have given informed consent for the study.

\section{Exclusion Criteria}

1. Cases of surgical jaundice who are unfit for the interventional diagnostic imaging. 
Annals of International Medical and Dental Research E-ISSN: 2395-2822 | P-ISSN: 2395-2814

Vol-8, Issue-2 | March-April 2022

DOI: 10.53339/aimdr.2022.8.2.12

Page no- 79-90 | Section- Research Article (General Surgery)

2. Patient with surgical jaundice having concomitant pre hepatic or hepatic jaundice.

3. Patient suffering from liver cirrhosis.

\section{Statistical Analysis}

All analysis was performed using SPSS version 20. Mean and standard deviation were calculated for quantitative data and frequency \& percentages were calculated for qualitative data.

\section{RESULTS}

[Table 1 and Figure 1] shows the frequency distribution of Sex, where maximum percentages of subjects were Females i.e. 56.8\%

[Table 2 and Figure 2] shows the frequency distribution of Age Group, where maximum percentages of subjects were 61 to 70 Age Group i.e. $34.09 \%$

[Table 3 and Figure 3] shows the frequency distribution of Gender followed by Benign and Maliganant, where maximum subjects were in Benign as Female i.e. 15

[Table 2 and Figure 2] shows the frequency distribution of Occupation, where maximum percentages of subjects were found in Service i.e. $45.5 \%$

[Table 4] shows the distribution of Clinical Preparation, where Jaundice were found in $100 \%$ subjects,Clay colored stool were in $93.2 \%$, Pruritis were in $68.2 \%$, Anorexia were in $72.7 \%$, Weight loss were in $31.8 \%$, Abdominal pain were in $61.4 \%$, scratch mark were in $61.4 \%$, Abdominal mass were in $31.8 \%$, Fever were in $6.8 \%$, Vomiting were in $22.7 \%$, Past medical history Recurrence were in $13.6 \%$ and Past surgical history were in 2.3 subjects.

[Table 5] shows the frequency distribution of USG whole abdomen, where maximum subjects were found in multiple stone with various size present in gall bladder with CBD stone present i.e . $34.05 \%$. 2nd most common finding GB sludge with diffuse wall thickening and size of stone present in CBD i.e. $31.78 \%$.

[Table 7] shows the frequency distribution of ETIOLOGY, where maximum subjects were found in Choledocholitheasis with Cholelitheasis i.e. $34.05 \%$. 2ND most common choledocholitheasis with obstructive jaundice i.e $31.78 \%$.

[Table 8] shows the frequency distribution of CECT Abdomen(as indicated), where maximum subjects were found in CA GB with hepatic infiltration causing bilobar non communicatig IHBR and compression of CBD i.e. $11.5 \%$

[Table 9] shows the frequency distribution of MRCP (as indicated), where 13.8\% were found in MRCP (as indicated) and 86.4\% were not found in MRCP (as indicated).

[Table 10] shows the frequency distribution of DIAGNOSIS, where maximum subjects were found in Choledocholitheasis with Cholelitheasis i.e. $34.05 \% .2$ nddiagnosis choledocholitheasis with obstructive jaundice $31.78 \%$.

[Table 11] shows the frequency distribution of Management, where ERCP was done in $59.09 \%$, Triple Bypass surgery was done in $0 \%$, Stenting was done in $63.36 \%$ and Palliative was done in $9.09 \%$ 
Annals of International Medical and Dental Research E-ISSN: 2395-2822 | P-ISSN: 2395-2814

Vol-8, Issue-2 | March-April 2022

DOI: 10.53339/aimdr.2022.8.2.12

Page no- 79-90 | Section- Research Article (General Surgery)

[Table 12] shows the frequency distribution of Surgery Done Cholecystectomy, where maximum subjects were found in ERCP with stenting i.e $29.55 \% .2$ nd common ERCP followed by lap cholecysectomy i.e $20.45 \%$. 3rd common open cholecystectomy with CBD exploration i.e $6.82 \%$ and lap cholecystectomy converted to open with CBD exploration i.e $6.82 \%$.
[Table 12 and Figure 4] shows the frequency distribution of HPE(if any), where $42.2 \%$ were found in CHRONIC CHOLE CYSTITIS.

[Table 13 and Figure 5] shows the frequency distribution of SURGERY, where maximum subjects were found in DEFINATIVE i.e. $63.63 \%$, and $9.09 \%$ in PALLIATIVE.

Table 1: Represent the frequency distribution of the cases according to Sex.

\begin{tabular}{|l|l|l|}
\hline Sex & Frequency & Percent \\
\hline F & 25 & 56.8 \\
\hline M & 19 & 43.2 \\
\hline Total & 44 & 100.0 \\
\hline
\end{tabular}

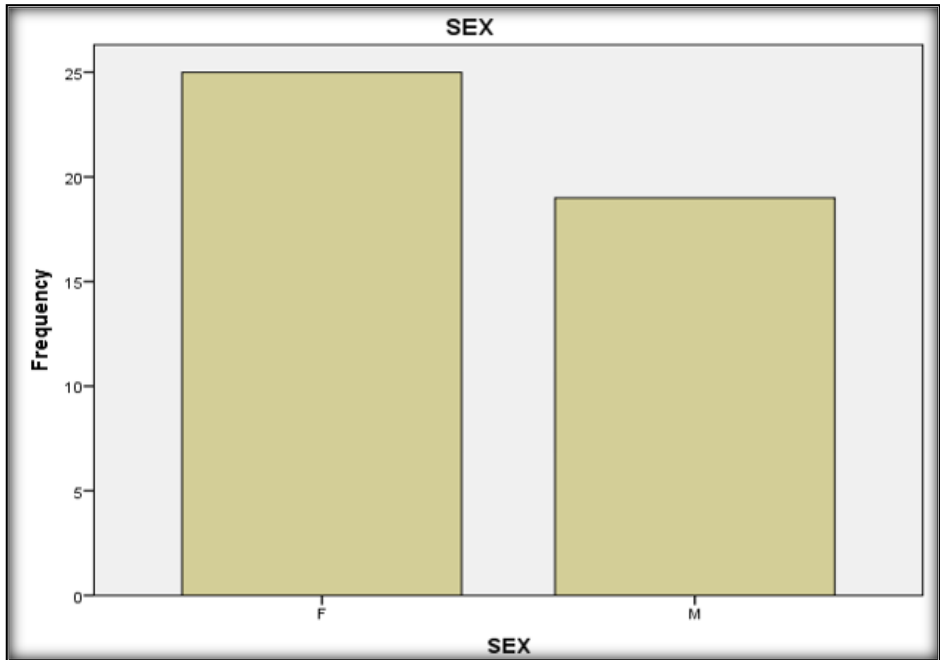

Figure 1:

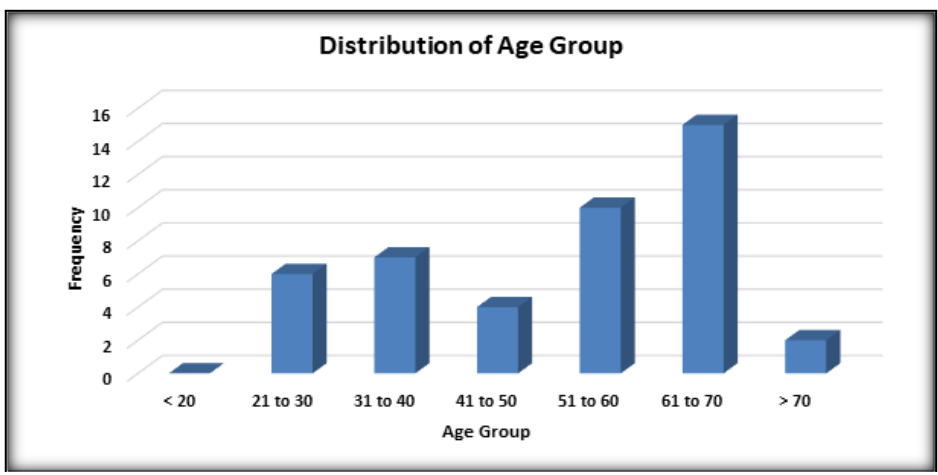

Figure 2:

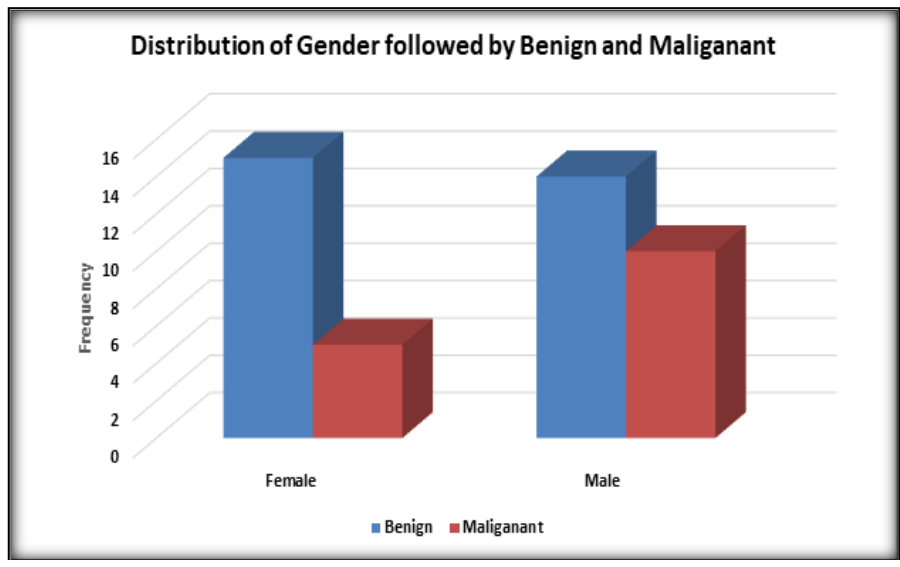

Figure 3:

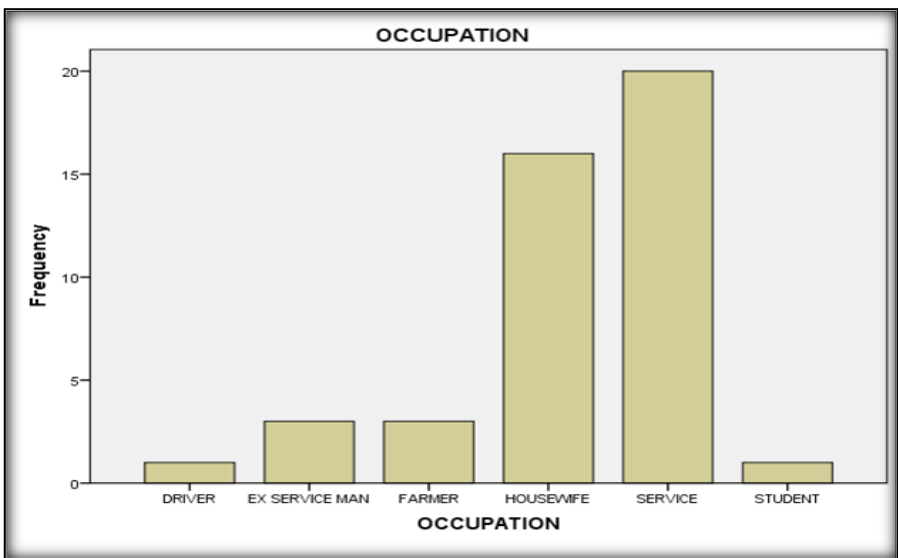

Figure 4: 
Annals of International Medical and Dental Research E-ISSN: 2395-2822 | P-ISSN: 2395-2814

Vol-8, Issue-2 | March-April 2022

DOI: 10.53339/aimdr.2022.8.2.12

Page no- 79-90 | Section- Research Article (General Surgery)

Table 2: Represent the frequency distribution of the cases according to Age Group.

\begin{tabular}{|l|l|l|}
\hline Age Group & Frequency & Percent \\
\hline$<20$ & 0 & 0.00 \\
\hline 21 to 30 & 6 & 13.64 \\
\hline 31 to 40 & 7 & 15.91 \\
\hline 41 to 50 & 4 & 9.09 \\
\hline 51 to 60 & 10 & 22.73 \\
\hline 61 to 70 & 15 & 34.09 \\
\hline$>70$ & 2 & 4.55 \\
\hline
\end{tabular}

Table 3: Represent the frequency distribution of the cases according to Gender followed by Benign and Maliganant

\begin{tabular}{|l|l|l|l|}
\hline & Female & Male & Total \\
\hline Benign & 15 & 14 & 29 \\
\hline Maliganant & 5 & 10 & 15 \\
\hline
\end{tabular}

Table 4: Represent the frequency distribution of Occupation.

\begin{tabular}{|l|l|l|}
\hline Occupation & Frequency & Percent \\
\hline Driver & 1 & 2.3 \\
\hline Ex Service Man & 3 & 6.8 \\
\hline Farmer & 3 & 6.8 \\
\hline Housewife & 16 & 36.4 \\
\hline Service & 20 & 45.5 \\
\hline Student & 1 & 2.3 \\
\hline Total & 44 & 100.0 \\
\hline
\end{tabular}

Table 5: Represent the frequency distribution of Clinical Presentation.

\begin{tabular}{|l|l|l|}
\hline Clinical Presentation & Frequency & Percent \\
\hline Jaundice & 44 & 100.0 \\
\hline Clay colored stool & 41 & 93.2 \\
\hline Pruritis & 30 & 68.2 \\
\hline Anorexia & 32 & 72.7 \\
\hline Weight loss & 14 & 31.8 \\
\hline Abdominal pain & 27 & 61.4 \\
\hline Scratch mark & 27 & 61.4 \\
\hline Abdominal mass & 14 & 31.8 \\
\hline Fever & 3 & 6.8 \\
\hline Vomiting & 10 & 22.7 \\
\hline Past medical history Recurrence & 6 & 13.6 \\
\hline Past surgical history & 1 & 2.3 \\
\hline
\end{tabular}


Annals of International Medical and Dental Research

E-ISSN: 2395-2822 | P-ISSN: 2395-2814

Vol-8, Issue-2 | March-April 2022

DOI: 10.53339/aimdr.2022.8.2.12

Page no- 79-90 | Section- Research Article (General Surgery)

Table 6: Represent the frequency distribution of USG whole abdomen.

USG whole abdomen

Mulitple stone in GB largest $12 \mathrm{~mm}$ with $11 \mathrm{~mm}$ stone in CBD +dilation max 22 to 1

$23 \mathrm{~mm}$

Multiple stone in GB largest $12 \mathrm{~mm}$ with $6 \mathrm{~mm}$ stone in CBD +dilatation max 11 to 1

$22 \mathrm{~mm}$

Mulitple stone in GB largest $13 \mathrm{~mm}$ with $6 \mathrm{~mm}$ stone in CBD +CBD dilatation max 1

$10 \mathrm{~mm}$

Multiple stone in GB largest 9mm with $7 \mathrm{~mm}$ stone in CBD+ dilatation max 10.9mm

Multiple stone in GB largest $12.9 \mathrm{~mm} w$ ith 2 to $3 \mathrm{~mm}$ stone in CBD dilatation $\max 1$

$9.7 \mathrm{~mm}$

Multiple stone in GB largest 14mm with 8mm stone in CBD + dilation max $10.9 \mathrm{~mm}$

Multiple stone in GB largest $14 \mathrm{~mm}$ with $12 \mathrm{~mm}$ stone in CBD+ dilatation max $10.9 \mathrm{~mm}$

Multiple stone in GB largest 12,5mm with $7 \mathrm{~mm}$ stone in CBD +dilatation max $8 \mathrm{~mm}$

Multiple stone in GB largest 9mm with CBD stone $8 \mathrm{~mm}$ dilated CBD $12 \mathrm{~mm}$ and 1

central IHBR with $8.6 \mathrm{~mm}$

Multiple tiny calculi 2 to $3 \mathrm{~mm}$ noted with in GB ,CBD dilated $7.9 \mathrm{~mm}$ with CBD stone 1

$6.5 \mathrm{~mm}$

Multiple stone in GB largest 13mmwith 6mm stone in CBD CBD dilatation max 10mm

Multiple stone 4 to $5 \mathrm{~mm}$, with CBD stone $8 \mathrm{~mm}$ with dilated CBD

Multiple stone 4 to $5 \mathrm{~mm}$, with CBD stone $8 \mathrm{~mm}$ with dilated CBD

Distal cholangiocarcinoma with upstream biliary dilation and nodular lesion in GB

Multiple calculi 5 to $17 \mathrm{~mm}$ in gb lumen multiple hypoechoic growth of size $17 * 12 \mathrm{~mm}$

in gb mass wall thickness $7 \mathrm{~mm}$

GB sludge with diffuse wall thickening with CBD dilated, 4mm stone present in CBD

GB sludge with diffuse wall thickening with CBD dilated, $7 \mathrm{~mm}$ stone present in CBD

Neoplastic growth of GB mass with infiltration and compression of CBD and bilobar

IHBR dilation present

Multiple calculi 5 to $17 \mathrm{~mm}$ in gb lumen multiple hypoechoic growth of size $17 * 12 \mathrm{~mm} 3$

in gb mass wall thickness $7 \mathrm{~mm}$

GB wall distended multiple stone within GB wall thickness $6.80 \mathrm{~mm}$ CBD dilated 1

$10.1 \mathrm{~mm}$ with $13 \mathrm{~mm}$ stone in CBD

GB wall distended with wall thickness $6.8 \mathrm{~mm}$ with CBD dilated $12.8 \mathrm{~mm}$ with $11 \mathrm{~mm} 1$

stone in CBD

GB wall distended with wall thickness $6.8 \mathrm{~mm}$ with CBDdilated $12.8 \mathrm{~mm}$ with $11 \mathrm{~mm} 1$

stone in CBD

GB wall distended multiple calculi with in GB wall thickness $6.8 \mathrm{~mm}$,CBD stone $8 \mathrm{~mm}, 1$

CBD dilated $10.5 \mathrm{~mm}$

GB sludge with diffuse wall thickening dilated CBD with $8 \mathrm{~mm}$ stone in CBD

GB sludge with diffuse wall thickening dilated CBD $12 \mathrm{~mm}$ and $11 \mathrm{~mm}$ stone in CBD

GB sludge with diffuse wall thickening, $7 \mathrm{~mm}$ stone in $\mathrm{CBD}+$ dilalation max $8 \mathrm{~mm}$

\begin{tabular}{|l|l|l}
\hline GB sludge with diffuse wall thickening with $8 \mathrm{~mm}$ stone in CBD + dilatation max 8 to & 1
\end{tabular}

Frequency

Percent

2.27

2.27

2.27

2.27

2.27

2.27

2.27

2.27

2.27

2.27

2.27

2.27

2.27

4.54

2.27

\begin{tabular}{l|l}
2 & 4.54 \\
1 & 2.27
\end{tabular}

2

3

2

4.54

6.82

15.91

6.82

2.27

2.27

2.27

2.27

2.27

2.27

2.27

2.27 
Annals of International Medical and Dental Research

E-ISSN: 2395-2822 | P-ISSN: 2395-2814

Vol-8, Issue-2 | March-April 2022

DOI: 10.53339/aimdr.2022.8.2.12

Page no- 79-90 | Section- Research Article (General Surgery)

\begin{tabular}{|l|l|l|}
\hline 9mm & & \\
\hline $\begin{array}{l}\text { GB sludge with diffuse wall thickening with 5mm stone in CBD +dilatation max } \\
\text { 9.0mm }\end{array}$ & 1 & 2.27 \\
\hline $\begin{array}{l}\text { GB sludge with diffuse wall thickening dilated CBD 10mm with CBD stone 10mm and } \\
\text { central IHBR }\end{array}$ & 2 & 4.54 \\
\hline $\begin{array}{l}\text { Periampullary CA with biliary and pancreatic ductal dilation as well as multiple } \\
\text { periportal lymphadenopathy }\end{array}$ & 1 & 2.27 \\
\hline Pancreatic mass head and uncinate process, fibrotic pancreatic head & 2 & 4.54 \\
\hline $\begin{array}{l}\text { Mild heapatomegaly gb is well distended with sludge,dilated biliary radicle and } \\
\text { infliration of CBD }\end{array}$ & 1 & 2.27 \\
\hline Dilated IHBRD with partially contracted GB & 2 & 4.54 \\
\hline Dilated proximal and mid CBD and bilobar IHBRD & 1 & 2.27 \\
\hline Total & 44 & 100.0 \\
\hline
\end{tabular}

Table 7: Represent the frequency distribution of Etiology.

\begin{tabular}{|l|l|l|}
\hline Etiology & Frequency & Percent \\
\hline Choledocholitheasis with Cholelitheasis & 15 & 34.05 \\
\hline Obstructive Jaundice with CAGB & 5 & 11.35 \\
\hline Choledocholitheasis with Obstructive Jaundice & 14 & 31.78 \\
\hline Cholangiocarcinoma with Obstructive Jaundice & 4 & 9.09 \\
\hline Metastatic CAGB & 2 & 4.55 \\
\hline Chronic Pancreatitis with Obstructive Jaundice & 1 & 2.27 \\
\hline Periampullary Carcinoma & 2 & 4.55 \\
\hline Periampullary Carcinoma with Cholelitheasis & 1 & 2.27 \\
\hline
\end{tabular}

Table 8: Represent the frequency distribution of CECT Abdomen(as indicated).

\section{CECT Abdomen (as indicated)}

A irregular ,asymmetric, hetrogenious enhancing thickening gb wall with hepatic infiltration + dilated CBD, CHD bilobar IHBRD

CA GB with hepatic infiltration causing bilobar non communicatig IHBR\& 5 compression of CBD

Distal CBD Cholangiocarcinoma with upstream biliary dilatation with locorigional 3 lymphadenopathy

Ill defined mass lesion arising from body \& wall of GB infiltrating the liver 1 parenchyma ( 7.2x4.9X 4.8) $\mathrm{mm}$ \& CHD

lobulated enhancing necrotic mass pancreatic head and uncenate process causing 1 biliary \& pancreatic duct obstruction

Mass lesion in GB $12 * 8 \mathrm{~mm}$ with IHBRD ,CBD $6.5 \mathrm{~mm}$

Mass lesion in GB6cm*5.8mm with IHBRD,CBD not dilated

Multiple small (5.5-6) mm intraluminal inclusion defect CBD measuring $7.0 \mathrm{~mm}$

Multiple tiny calculi (4-5) mm noted with in GB, CBD dilated (10.0) $\mathrm{mm}$

no

\begin{tabular}{|l|l|}
\hline Frequency & Percent \\
\hline 1 & 2.3 \\
\hline 5 & 9.1 \\
\hline 3 & 2.3 \\
\hline 1 & 2.3 \\
\hline 1 & 2.3 \\
\hline 1 & 2.3 \\
\hline 1 & 2.3 \\
\hline 1 & 2.3 \\
\hline 1 & 2.3 \\
\hline 26 & 47.7 \\
\hline
\end{tabular}

Copyright: ()The author(s), published in Annals of International Medical and Dental Research, Vol-8, Issue-2. This is an open access article under the Attribution-Non Commercial 2.0 Generic (CC BY-NC 2.0) license. (https://creativecommons.org/licenses/by-nc/2.0/) 
Annals of International Medical and Dental Research E-ISSN: 2395-2822 | P-ISSN: 2395-2814

Vol-8, Issue-2 | March-April 2022

DOI: 10.53339/aimdr.2022.8.2.12

Page no- 79-90 | Section- Research Article (General Surgery)

neoplastic Thickening involving CHD, Cystic duct and proximal CBD with biliary 1 back pressure changes

Periampullary $\mathrm{Ca}$ with biliary \& pancreatic ductal dilatation as well as multiple 1 periportal lymphadenopathy

Small periampullary mass with involment of duodenum 2 nd part \& severe biliary 1 back pressure change with cholelithiasis

Total

\begin{tabular}{|l|l|}
\hline 1 & 2.3 \\
\hline 1 & 2.3 \\
\hline 1 & 2.3 \\
\hline 44 & 100.0 \\
\hline
\end{tabular}

Table 9: Represent the frequency distribution of $\mathrm{MRCP}$ (as indicated).

\section{MRCP (as indicated)}

Abrupt tappering at CHD,CBD stricture, obstructive biliopathy ,contracted GB

Cholelithiasis with CBD dilation (14.6) $\mathrm{mm}$ with upstream bilobar IHBRD

\begin{tabular}{|l|l|l|} 
& Frequency & Percent \\
\hline with distal & 1 & 2.3 \\
& 1 & 2.3 \\
\hline \&BR & 1 & 2.3 \\
\hline \& upstream & 1 & 2.3 \\
\hline & & 2.3 \\
\hline & 1 & 2.3 \\
\hline & 38 & 86.4 \\
\hline
\end{tabular}

Table 10: Represent the frequency distribution of Diagnosis.

\section{Diagnosis}

Choledocholitheasis with Cholelitheasis

Cholangiocarcinoma with Obstructive Jaundice

Metastatic CAGB with Obstructive Jaundice

Obstructive Jaundice with CAGB

Choledocholitheasis with Obstructive Jaundice

Chronic Pancreatitis with Obstructive Jaundice

Periampullary Mass with Cholelitheasis

Periampullary Carcinoma

\begin{tabular}{|l|l|}
\hline Frequency & Percent \\
\hline 15 & 34.05 \\
\hline 4 & 9.09 \\
\hline 2 & 4.55 \\
\hline 5 & 11.35 \\
\hline 14 & 31.78 \\
\hline 1 & 2.27 \\
\hline 1 & 2.27 \\
\hline 2 & 4.55 \\
\hline
\end{tabular}

Table 11: Represent the frequency distribution of Management.

\begin{tabular}{|l|l|l|l|}
\hline Management & Findings & Frequency & Percent \\
\hline \multirow{2}{*}{ ERCP } & Done & 26 & 59.09 \\
\cline { 2 - 4 } & Not Done & 18 & 40.09 \\
\hline \multirow{2}{*}{ Triple Bypass surgery } & Done & 0 & 0 \\
\cline { 2 - 4 } & Not Done & 44 & 100 \\
\hline \multirow{2}{*}{ Stenting } & Done & 28 & 63.63 \\
\cline { 2 - 4 } & Not Done & 16 & 36.36 \\
\hline \multirow{2}{*}{ Palliative } & Done & 4 & 9.09 \\
\cline { 2 - 4 } & Not Done & 40 & 90.90 \\
\hline
\end{tabular}


Annals of International Medical and Dental Research E-ISSN: 2395-2822 | P-ISSN: 2395-2814

Vol-8, Issue-2 | March-April 2022

DOI: 10.53339/aimdr.2022.8.2.12

Page no- 79-90 | Section- Research Article (General Surgery)

Table 12: Represent the frequency distribution of SURGERY DONE

\begin{tabular}{|l|l|l|}
\hline Surgery Done & Frequency & Percent \\
\hline Open cholecystectomy with CBD exploration & 3 & 6.82 \\
\hline ERCP followed by lap cholecysectomy & 9 & 20.45 \\
\hline Patient referred to higher centre & 16 & 36.36 \\
\hline Lap cholecystectomy converted to open chole with CBD exploration & 3 & 6.82 \\
\hline ERCP with Stenting & 13 & 29.55 \\
\hline
\end{tabular}

Table 13: Represent the frequency distribution of HPE (if any).

\begin{tabular}{|l|l|l|}
\hline HPE (if any) & Frequency & Percent \\
\hline Chronic Chole Cystitis & 15 & 34.09 \\
\hline No & 29 & 65.91 \\
\hline
\end{tabular}

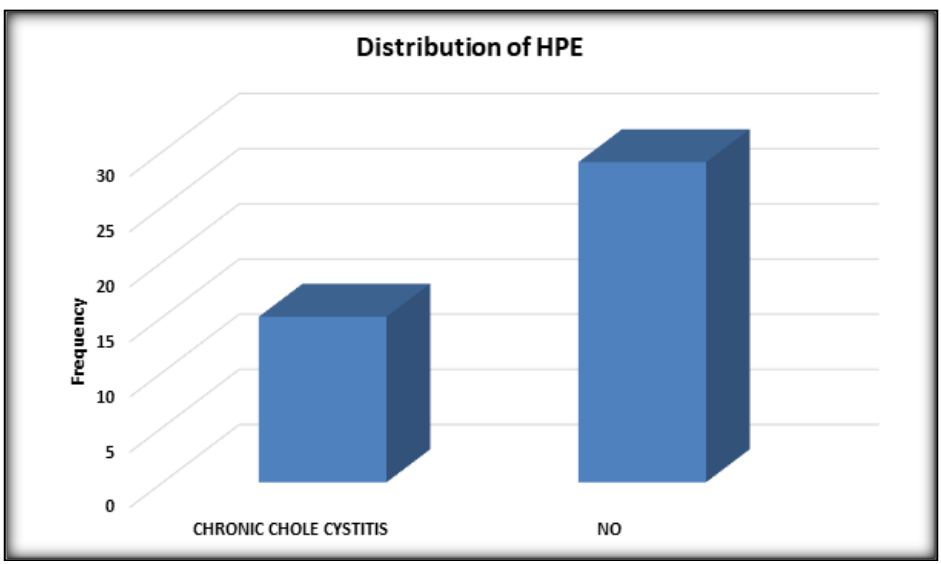

Figure 5:

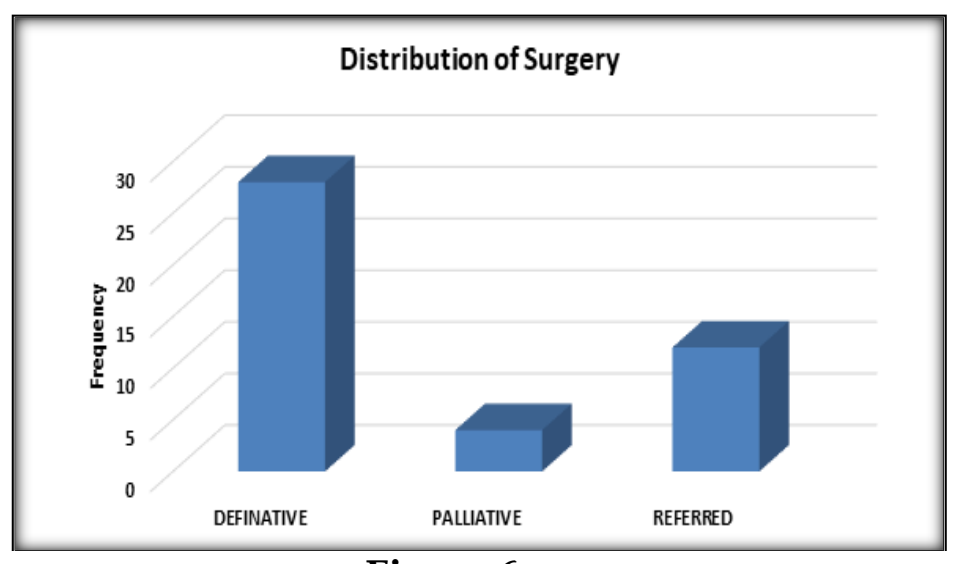

Figure 6:

Table 13: Represent the frequency distribution of Surgery.

\begin{tabular}{|l|l|l|}
\hline Surgery & Frequency & Percent \\
\hline Definative & 28 & 63.63 \\
\hline Palliative & 4 & 9.09 \\
\hline Referred & 12 & 27.27 \\
\hline
\end{tabular}

\section{DISCUSSION}

In my study Forty four study subjects included out of which $56.8 \%$ were female and $43.2 \%$ were male. As per the frequency distribution the maximum percentage of the subjects belong from the age group of 61 to 70 which accounted for $34.09 \%$ whereas the minimum number of study subjects belong from the age group of more than 70. Similar to my study, the researchers Saddique \& Iqbal, considered 24 cases of surgical jaundice and the mean age of their patients were 41.12 years.As per the study $54.17 \%$ of the cases where having jaundice because of malignancy whereas $37.5 \%$ of the cases had stones inside the common bile duct. The remaining cases in their study were having amoebic liver abscess. 
Annals of International Medical and Dental Research

E-ISSN: 2395-2822 | P-ISSN: 2395-2814

Vol-8, Issue-2 | March-April 2022

DOI: 10.53339/aimdr.2022.8.2.12

Page no- 79-90 | Section- Research Article (General Surgery)

All the patients who are suffering from stones in the CBD have been treated through cholecystectomy along with open CBD exploration and the ones who were having amoebic liver abscess were provided with aspiration of drainage for their relief. [8] In my study as per the distribution of the cases benign causes are more in female while malignant are more in males. Percentage of benign cases were more than malignant cases. Contrastingly the researchers Patra et al.also found out that for their study the benign cases were less than malignant ones as it was observed in $58 \%$ of the cases. ${ }^{[9]}$ In our study as per the Occupation of the study subjects it has been noticed that most of the study subjects were in service accounted for $45.5 \%$ and it was followed by housewives which was $36.4 \%$. While in the study of the researchers Sharma \& Thapar, it was observed that the majority of the patients belong to housewives which accounted for $45.3 \%$.[10] In our study the frequency distribution of the clinical presentation jaundice was seen in $100 \%$, that was followed by clay coloured stool in $93.2 \%$, anorexia were in $72.7 \%$, Pruritus were found in $68.2 \%$, Abdominal pain and scratch mark both were in $61.4 \%$, Weight loss got observed in $31.8 \%$, Abdominal mass were in $31.8 \%$, Vomiting was common in $22.7 \%$ and Fever were in $6.8 \%$. Even Past medical history Recurrence were in $13.6 \%$ and Past surgical history were in $2.3 \%$ of the subjects. In our study Frequency distribution according to the USG of the whole abdomen shows that majority of the subjects were having multiple stones which were various in size in their gallbladder and stone in CBD was present in $34.05 \%$ after that the second most common finding was the gall bladder sludge along with diffuse wall thickening and various size of the stones present in the CBD in $31.78 \%$. Neoplastic growth of the gallbladder mass along with the CBD compression and the Bilobar intrahepatic biliary radical dilatation was observed in $4.54 \%$ of the cases.Srinidhi \& Hosmani, studied 30 patients having obstructive jaundice and they found out that malignant diseases are one of the most common causes that results in obstructive jaundice which mostly affects the age group of 55 to 74 years.For their patients, jaundice was the most common clinical feature and they also noticed that one of the most effective modality for the diagnosis was USG abdomen.[11,12] In our study the representation of the frequency distribution as per the etiology shows that maximum of the subjects were having Choledocholitheasis along with Cholelitheasis that are counted in $34.05 \%$ of the study cases. And choledocholeitheasis with obstructive jaundice turned out to be the second most common etiology with $31.78 \%$.after that jaundice with Carcinoma of gall bladder became the third most common etiology with 11.35\% Umeshchandra \& Maitra, noticed that the abdomen pain was being observed in 73.3 $\%$ of the patients whereas dyspepsia was present in $60 \%$ of the patient. And in $10 \%$ of the patients having high risk of malignancy . They also found that fever came up to be one of the very common types factor.[13]

In our study some interesting facts came out in the distribution of the frequency of Management. The representation shows that ERCP was done in $59.09 \%$ of the patients whereas triple Bypass surgery was done in none of them. After that Stenting was done in $63.63 \%$ of the study subjects whereas it was not 
Annals of International Medical and Dental Research

E-ISSN: 2395-2822 | P-ISSN: 2395-2814

Vol-8, Issue-2 | March-April 2022

DOI: 10.53339/aimdr.2022.8.2.12

Page no- 79-90 | Section- Research Article (General Surgery)

done in $36.36 \%$. Prabakar \& Raj, shows that in their study ERCP was being given the maximum attention as $62 \%$ of their patients had pursued this and the second most important one was stenting that was performed in $34 \%$ of the patients. [14]

In our study the representation of the frequency distribution of the surgery done came up with the results that majority of the study subjects that is $20.45 \%$ had treated with ERCP followed by lap cholecystectomy then both lap cholecystectomy converted to open cholecystectomy with CBD exploration and open cholecystectomy with CBD exploration found in $6.82 \%$ of the study subjects each. ERCP with stenting was done for $29.55 \%$ of the cases. Similarly the researchers Tripathi et al., Noticed that maximum of their cases was being performed with ERCP and accounted for $28.3 \%$. ${ }^{[15]}$ Lastly, in the Representation of the frequency distribution of surgery we noticed that maximum of the patients were treated with definitive managment which was done in $63.63 \%$ of them and $9.09 \%$ of the patients were

\section{REFERENCES}

1. Anand S, Panda C, Senapati AT, Behera MR. A study on incidence, clinical profile, and management of obstructive jaundice. Evid Based Med Health. 2016;3(59):3139-3145. http://dx.doi.org/10.18410/jebmh/2016/683

2. Mangam NP, Dakhore SD, Bodade RM, Dhurve AS, Dhoran AP. Presentation, Etiology and management of obstructive jaundice a prospective study. J Med Sci Clin Res. 2018;06(07):207. https://dx.doi.org/10.18535/jmscr/v6i7.36

3. Khan ZA. Clinical profile of patients with obstructive jaundice a surgeons perspectives. Int Surg J. 2019;6(6):1876. https://dx.doi.org/10.18203/2349-2902.isj20192060 treated with palliative treatment and 27.27\% had referred to higher centre.

\section{CONCLUSIONS}

The USG of the abdomen is also helpful that came up with identifying multiple stones of various sizes that are present in CBD and gall bladder. Maximum of the subjects having obstructive jaundice was due to Choledocholitheasis with cholelitheasis their etiology and second etiology was due to choledocholitheasis alone.Finally, it can be concluded that for the cases of malignant surgical jaundice good survival benefit usually depends upon the detection of the disease early during the course period. It has also been found that in malignant cases the stage of disease with jaundice were advanced. As per our study results it has been observed that there are various etiological factors contributing to development of surgical jaundice which needs multiple modes of precise investigations and further evaluations further studies and research needed to cover various factor responsible for surgical jaundice.

4. Selvasekaran R, Nagalakshmi G, Anandan H. Clinical spectrum of presentation of obstructive jaundice in inflammation, stone Diease and malignancy. Int J Sci Study. 2017;5(4):10.

5. Padhy BP, Murmu D, Samal D, Jha S. Clinical study of surgical jaundice: an institutional experience. Int Surg J. 2017;5(1):138-142. http:/ / dx.doi.org/10.18203/2349-2902.isj20175883

6. Gupta P, Gupta J, Kumar-M P. Imaging in obstructive jaundice: what a radiologist needs to know before doing a percutaneous transhepatic biliary drainage. J Clin Interv Radiol ISVIR. 2020;4(01):31-37.

7. Björnsson E, Gustafsson J, Borkman J, Kilander A. Fate of patients with obstructive jaundice. J Hosp 
Annals of International Medical and Dental Research

E-ISSN: 2395-2822 | P-ISSN: 2395-2814

Vol-8, Issue-2 | March-April 2022

DOI: $10.53339 /$ aimdr.2022.8.2.12

Page no- 79-90 | Section- Research Article (General Surgery)

Med. 2008;3(2):117-23. Fate of patients with obstructive jaundice

8. Saddique M, Iqbal SA. Management of Obstructive Jaundice: Experience in a tertiary care surgical unit. Pakistan J Surg. 2007;23(1):23-5.

9. Patra KK, Saha S, Halder S, Banerjee C. A Prospective Study on Clinical Profile and Management of Obstructive Jaundice. Int J Health Clinical Res. 2021;4(9):233-236.

10. Sharma A, Thapar K. A prospective observational study of thrombocytopenia in high risk neonates in a tertiary care teaching hospital. Sri Lanka J Child Health. http://doi.org/10.4038/sljch.v44i4.8045

11. Laghari AA, Laghari QA, Shaikh AA, Muneer A, Pandhi M. Clinical Presentation and different Treatment Modalities of Obstructed Jaundice. J

Pharm Res Int. 2020;199-203.
https://doi.org/10.9734/jpri/2020/v32i1730747

12. Srinidhi M, Hosmani R. A study of obstructive jaundice with focus on predictive factors for outcome. J Evol Med Dent Sci. 2014;3(29):8040-8048.

13. Umeshchandra DG, Maitra J. Clinical study of obstructive jaundice at Basaveshwar Teaching and General Hospital, Gulbarga. SAS J Surg. 2015;1(3):105-118.

14. Prabakar A, Raj RS. Obstructive jaundice: a clinical study. J Evol Med Dent Sci. 2016; 5(28):1423-1430.

15. Tripathi C, Yeola M, Gharde P. To Study the clinical Profile of the Patients with Obstructive Jaundice. Eur J Biomed. 2019; 6(2): 343-355.

Source of Support: Nil, Conflict of Interest: None declared 